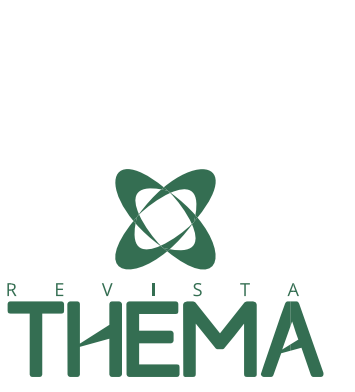

\title{
Implicações das tecnologias e da organização escolar no aprender matemática: o olhar do professor
}

\section{Implications of technologies and school organization in learning mathematics: teacher's look}

Aline Cardoso de Oliveira Macedo후 Débora Pereira Laurino²

\section{RESUMO}

Para grande parte dos alunos do Ensino Médio, utilizar as várias tecnologias existentes não é desafio. 0 desafio consiste na escolha das tecnologias que eles empregam para o aprender. Para tentar compreender essas escolhas, trazemos o presente artigo que analisa os discursos, organizados a partir de entrevistas semiestruturadas, feitas com professores de Matemática de um Instituto Federal. As perguntas versaram sobre a percepção do comprometimento de seus alunos com a sua própria aprendizagem e as tecnologias escolhidas no aprender. Para organizar as discursividades, escolhemos a técnica Discurso do Sujeito Coletivo, proposta por Fernando Lefèvre e Ana Maria Lefèvre. Ao analisarmos esses discursos, com o aporte teórico da Biologia do Conhecer desenvolvida por Humberto Maturana e Francisco Varela, compreendemos que o professor está procurando maneiras diferentes para trabalhar, visando atender às necessidades dos seus alunos, pois trabalhar pedagogicamente com a tecnologia requer apropriação da mesma. Percebemos que o comprometimento de alunos e professores é ponto de partida para que se ampliem as possibilidades de cooperação e de significados do próprio aprender Matemática. É em um ambiente cooperativo que, professores e alunos, poderão conviver e encontrar as tecnologias que mediarão esse aprender.

Palavras-chave: Aprender; Matemática; Tecnologias.

\begin{abstract}
For most of the high school students to use various technologies is not challenging. The challenge is choosing the technologies they employ to learn. To try to understand the choices this article analyzes the speeches, organized from semi-structured interviews, made with mathematics teachers of a Federal Institute. The questions were about the perception of commitment of their students with their own learning and the technologies they chose to learn. In order to organize the discourses, we chose the Collective Subject Discourse technique, proposed by Fernando Lefèvre and Ana Maria Lefèvre. Analyzing these speeches, with the theoretical support of the Biology of Knowledge developed by Humberto Maturana e Francisco Varela, we understand that the teacher is looking for different ways to work, looking forward to supply the needs of their students, because working pedagogically with technology requires ownership of it. We realize that the commitment of students and teachers is the starting point to expand the possibilities of cooperation and meanings of own learning mathematics process. It is in a collaborative environment, that teachers and students can socialize and find the technologies that will mediate this learning.
\end{abstract}

Keywords: Learning; Mathematics; Technologies.

\footnotetext{
${ }^{1}$ IFRS - Instituto Federal de Educação, Ciência e Tecnologia do Rio Grande do Sul, Rio Grande/RS - Brasil.

2 FURG - Universidade Federal do Rio Grande, Rio Grande/RS - Brasil.
} 


\section{INTRODUÇÃO}

O estudo do aprender não deveria estar dissociado ao uso de tecnologias, porque nos utilizamos de várias delas como auxiliares nesse processo. No contexto da educação formal empregamos desde as mais conhecidas, como o quadro, o giz, o livro, o caderno e o lápis; e também as digitais tais como: editores de textos, calculadoras, simuladores, sites, vídeos e ambientes virtuais de aprendizagem disponíveis na internet. Elas estão presentes, nesse contexto, desde a elaboração das aulas até a emissão da certificação de conclusão do curso (KENSKI, 2007). Professores e alunos escolhem qual dessas tecnologias desejam, ou necessitam, em diferentes momentos do processo educacional.

Outro ponto indissociável do aprender é o ambiente escolar, no qual esse aprender é suscitado. De forma geral, esse ambiente tem sofrido várias alterações, inclusive algumas impostas pela legislação. Tais modificações estão acontecendo com grande rapidez, trazendo estranhamento a alguns professores, seja por incompreensão da legislação ou pela falta de formação específica para lidar com situações que emergem no dia-a-dia de sua ação docente. A exemplo podemos citar: o acesso aos alunos com necessidades especiais, sejam eles deficientes ou superdotados, ao ensino na rede regular e a Lei n.12.711 de agosto de 2012, que cria políticas de inclusão social nas quais são oferecidas possibilidades de ingresso, nas escolas da rede federal de ensino técnico de nível médio, à alunos que cursaram o ensino fundamental em escolas públicas. Trazemos esses dois pontos como interligados ao aprender pois eles surgiram no conversar com os professores de Matemática de um Instituto Federal de Educação, que trabalham com os alunos do Ensino Técnico Integrado ao Ensino Médio. Sendo assim, neste artigo problematizamos sobre o comprometimento do estudante com o seu aprender e o relacionamos com as tecnologias que são utilizadas por ele no aprender Matemática. Também discutimos sobre o quanto as alterações na legislação estão modificando a organização escolar e a ação docente do professor de Matemática.

Para analisar essas conversas, realizadas com os professores de Matemática, utilizamos a teoria da Biologia do Conhecer, desenvolvida por Humberto Maturana e Francisco Varela, que perpassa todo o texto e para organizar as discursividades dos professores, usamos a técnica do Discurso do Sujeito Coletivo proposta por Fernando Lefèvre e Ana Maria Lefèvre. Assim, elaboramos esse artigo em seções. Na próxima seção trazemos algumas reflexões sobre o aprender; na seguinte apresentamos a técnica de construção dos discursos; após mostramos os discursos elaborados e suas respectivas análises; apresentamos nossas considerações e sugestões; e finalizamos apontando as referências utilizadas na confecção desse trabalho.

\section{SOBRE O APRENDER}

Aprendemos no viver e no conviver, ao partilharmos experiências com o outro, pois "todo fazer é um conhecer e todo conhecer é um fazer" (MATURANA e VARELA, 2001, p.31). Segundo esses autores, o ser humano aprende em congruência com o meio, ao observar os outros e ao experienciar determinadas situações. A sala de aula é um dos espaços que compõe esse meio, as disposições interativas, as tecnologias, os recursos e as emoções presentes no ambiente educacional propiciam determinadas situações e experiências que podem levar ao estabelecimento de novas relações e compreensões que ocorrerão na congruência com esse espaço.

Maturana (2014a) também nos descreve que somos responsáveis pelo nosso próprio aprender "porque a responsabilidade tem a ver com os desejos das pessoas, com o dar-se conta de que as 
consequências de seus atos são desejáveis" (p.52). Se o estudante deseja o aprender, não pode delegar a responsabilidade do seu aprender a outrem, precisa ser o protagonista nessa ação e darse conta de que são suas atitudes na congruência com o meio que suscitarão compreensões e aprenderes. Cada estudante é responsável pelos seus aprenderes, e a consciência dessa responsabilidade passa pelo respeito aos seus desejos em um espaço do aprender que possibilite 0 fazer, o experienciar e o responsabilizar-se. De acordo com Maturana (2014b), uma explicação de um fenômeno só é validada se aceita por um observador. Sendo assim, para que a explicação de um professor seja validada depende que seus alunos a validem, pensem sobre ela, decidam se ela é aceitável e coerente para si.

A forma com que interagimos com o mundo é pessoal, a "nossa experiência está indissoluvelmente atrelada a nossa estrutura" (MATURANA e VARELA, 2001, p.28). Essa premissa nos remete a pensar que nós professores podemos apenas perturbar os nossos alunos com desafios e indagações, tentar fazer com que eles se interessem pelo que estamos propondo, porém, o modo como cada um deles vai reagir as perturbações é único. Isso não nos exime de nossa ação de ensinar, ao contrário nos convoca a conhecer os estudantes para que possamos, no conversar, compreendê-los e desafiá-los.

É no conversar que podemos desencadear perturbações pois no conversar lançamos mão da linguagem, que segundo Maturana (2009) é o que nos diferencia como ser humano. Para este autor o conversar é o entrelaçamento do linguajear com o emocionar pelo qual nos fazemos compreender e viver em sociedade. $O$ autor também ressalta que o linguajear não está associado à fala e sim com as nossas posturas no conversar. Deste modo, a emoção em que o indivíduo se encontra em um momento é fator determinante para sua ação ou indiferença frente a uma situação. Segundo Maturana (2009, p.16) "as emoções são disposições corporais que determinam ou especificam domínios de ações". Nesta perspectiva, podemos observar se alguém está se sentindo incomodado em uma sala de aula, se está com sono, se demonstra interesse pelo assunto que está sendo discutido pela emoção expressada. Essas emoções fazem com que, quando expostos a uma mesma situação, em diferentes momentos, tenhamos reações diferentes frente a essa situação, influenciando nosso linguajear.

Nossos estudos sobre a Biologia do Conhecer ${ }^{3}$, nos levou a compreender que aprendemos quando algumas perturbações nos levam a uma reformulação da experiência vivida, quando conseguimos estabelecer novas relações com conceitos já compreendidos e ressignificá-los, assim esse novo saber passa a compor o nosso mundo, provocando uma mudança de comportamento. Nossas experiências são ações no mundo e dependentes de nossas emoções, assim, podemos dizer que o que aprendemos depende de nossas emoções. Tal entendimento funda nossa discussão sobre o aprender e sobre como as tecnologias podem auxiliar no aprender matemática dos nossos estudantes.

Para conversar com os professores sobre o ambiente escolar e o uso das tecnologias pelos alunos em relação a seus aprenderes matemáticos, na seção seguinte, detalhamos as questões que balizaram essa conversa e o operar da técnica para a construção dos discursos coletivos que suscitaram as análises desse estudo.

\footnotetext{
${ }^{3}$ A Biologia do Conhecer é um modo de ver a fenomenologia dos seres vivos em geral e dos seres humanos em particular, é o nome dado ao conjunto das ideias de Humberto Maturana e Francisco Varela. É uma explicação do que é o viver e, ao mesmo tempo, uma explicação da fenomenologia observada no constante vir-a-ser dos seres vivos no domínio de sua existência.
} 


\section{ORGANIZANDO O CONVESAR}

Compreender o aprender se faz necessário para quem tem comprometimento com o ofício de educador. Interessam-nos questões relacionadas ao aprender de cada estudante, sua responsabilidade com a aprendizagem associada às tecnologias escolhidas para auxiliá-los no aprender Matemática.

Para isso, começamos o nosso estudo conversando, a partir de questões semiestruturadas, com cinco professores de Matemática de um Instituto Federal de Educação que trabalham com o Ensino Médio integrado ao Ensino Técnico, atendendo a todos os cursos oferecidos pela instituição nessa modalidade. Essas conversas foram gravadas e posteriormente transcritas, e tiveram por base as seguintes questões: 1) Como você percebe o comprometimento dos seus alunos com a sua própria aprendizagem? Por quê?; 2) Quais são as tecnologias utilizadas pelos seus alunos como auxiliares no processo da aprendizagem da Matemática?; 3) O que, na sua opinião, pode ser oferecido aos seus alunos para auxiliar na aprendizagem da Matemática?; e 4) Existe algo mais que gostaria de falar sobre aprendizagem? A primeira questão já foi por nós problematizada e analisada em uma outra publicação. No presente artigo nos propomos analisar e discutir as demais questões.

Com a intenção de entender esse coletivo de professores escolhemos a técnica do Discurso do Sujeito Coletivo (DSC), apresentada por Fernando Lefevre e Ana Maria Lefevre. Essa técnica constitui-se em um método de análise conhecido por propor um modo de organização e tabulação de dados qualitativos de natureza verbal, obtidos de depoimentos, de onde extraímos elementos chamados de expressões-chave (ECH), ideias centrais (IC) e ancoragens (AC), com a intenção de montar um discurso que represente a opinião dessa coletividade (LEFEVRE e LEFEVRE, 2005). Organizamos, inicialmente, esses dados em uma tabela chamada Instrumento de Análise do Discurso 1 (IAD1). Nessa tabela também aparece uma coluna chamada de código, que serve para agrupar as ECH de acordo com as IC identificadas. A seguir mostramos um recorte desse processo de organização dos registros discursivos.

Tabela 1- Instrumento de Análise do Discurso 1

\begin{tabular}{|l|l|l|c|}
\hline \multicolumn{1}{|c|}{ Expressões Chave } & \multicolumn{1}{|c|}{$\begin{array}{c}\text { Ideias } \\
\text { centrais }\end{array}$} & Ancoragem & Código \\
\hline $\begin{array}{l}\text { Algo que seria bastante útil para nós seria lousa interativa, } \\
\text { que seria um recurso extremamente interessante facilitaria } \\
\text { com o professor o fato de ter essa lousa interativa. Outra } \\
\text { situação seria se tivesse laboratório de informática com mais } \\
\text { disponibilidade de horários }\end{array}$ & Sugestões & $\begin{array}{l}\text { Tecnologias como } \\
\text { recuso didático }\end{array}$ & A \\
\hline $\begin{array}{l}\text { eles trocarem ideia entre eles, se unissem mais. Tem alunos } \\
\text { que se dão muito bem, que sabem bastante Matemática, } \\
\text { que tem facilidade. Eles poderiam ajudar aos outros. Eles } \\
\text { procurarem na internet sites confiáveis, pedindo a nossa } \\
\text { ajuda. Irem na biblioteca pegar livros, perguntando o nosso } \\
\text { auxílio, perguntando a nossa indicação, a gente indicaria } \\
\text { bons livros para eles terem um norte no estudo. Também a } \\
\text { utilizar softwares, jogos matemáticos tem muita coisa né? }\end{array}$ & Sugestões & $\begin{array}{l}\text { Comprender na } \\
\text { convivência }\end{array}$ & A \\
\hline $\begin{array}{l}\text { Se o trabalho no primeiro ano fosse mais acolhedor, mais } \\
\text { voltado para o aluno assim de fazer o cara entender a }\end{array}$ & Sugestões & $\begin{array}{l}\text { Aceitar o outro } \\
\text { como legítimo }\end{array}$ & A \\
\hline
\end{tabular}




\begin{tabular}{|l|l|l|l|}
\hline $\begin{array}{l}\text { matéria, oferecer mais atendimento, mais reforço, trazer } \\
\text { recursos didáticos para que eles possam aprender, eu acho } \\
\text { que isso favoreceria. Turmas menores, por exemplo, não } \\
\text { posso ter uma turma com 35 alunos e duas inclusões em } \\
\text { uma mesma sala }\end{array}$ & & & \\
\hline $\begin{array}{l}\text { Talvez com a Lousa digital, tenha um apelo..., mas eu não } \\
\text { sei se mudaria muita coisa mesmo. }\end{array}$ & Sugestões & $\begin{array}{l}\text { Tecnologias como } \\
\text { recuso didático }\end{array}$ & A \\
\hline $\begin{array}{l}\text { a própria reformulação da divisão de conteúdos, ementa das } \\
\text { disciplinas }\end{array}$ & $\begin{array}{l}\text { Mudança de } \\
\text { currículo }\end{array}$ & Pensar sobre & B \\
\hline $\begin{array}{l}\text { Eu acho que o ideal, em primeiro seria favorável a uma } \\
\text { mudança de currículo. }\end{array}$ & $\begin{array}{l}\text { Mudança de } \\
\text { currículo }\end{array}$ & Pensar sobre & B \\
\hline
\end{tabular}

Fonte: Informações da pesquisa organizadas pelas autoras, 2016.

A próxima etapa é montar a tabela chamada Instrumento de Análise do Discurso 2 (IAD2), em que agrupamos as ECH, sobre uma mesma IC, para então procedermos a elaboração do DSC.

Tabela 2- Instrumento de Análise do Discurso 2

\begin{tabular}{|c|c|}
\hline Expressões Chave & Discurso \\
\hline $\begin{array}{l}\text { Algo que seria bastante útil para nós seria lousa } \\
\text { interativa, que seria um recurso extremamente } \\
\text { interessante facilitaria com o professor o fato de ter } \\
\text { essa lousa interativa. Outra situação seria se tivesse } \\
\text { laboratório de informática com mais disponibilidade } \\
\text { de horários } \\
\text { eles trocarem ideia entre eles, se unissem mais. Tem } \\
\text { alunos que se dão muito bem, que sabem bastante } \\
\text { Matemática, que tem facilidade. Eles poderiam } \\
\text { ajudar aos outros. Eles procurarem na internet sites } \\
\text { confiáveis, pedindo a nossa ajuda. Irem na biblioteca } \\
\text { pegar livros, perguntando o nosso auxílio, } \\
\text { perguntando a nossa indicação, a gente indicaria } \\
\text { bons livros para eles terem um norte no estudo. } \\
\text { Também a utilizar softwares, jogos matemáticos tem } \\
\text { muita coisa né? } \\
\text { Se o trabalho no primeiro ano fosse mais acolhedor, } \\
\text { mais voltado para o aluno assim de fazer o cara } \\
\text { entender a matéria, oferecer mais atendimento, mais } \\
\text { reforço, trazer recursos didáticos para que eles } \\
\text { possam aprender, eu acho que isso favoreceria. } \\
\text { Turmas menores, por exemplo, não posso ter uma } \\
\text { turma com } 35 \text { alunos e duas inclusões em uma } \\
\text { mesma sala }\end{array}$ & $\begin{array}{l}\text { Tem alunos que sabem bastante Matemática, que } \\
\text { tem facilidade. Eles poderiam ajudar aos outros, } \\
\text { procurarem na internet sites confiáveis, pedindo a } \\
\text { nossa ajuda. Irem na biblioteca pegar livros, } \\
\text { perguntando a nossa indicação, a gente indicaria } \\
\text { bons livros para eles terem um norte no estudo. Algo } \\
\text { que seria bastante útil para nós seria lousa interativa, } \\
\text { que seria um recurso extremamente interessante, } \\
\text { mas eu não sei se mudaria muita coisa mesmo. Outra } \\
\text { situação seria se tivesse laboratório de informática } \\
\text { com mais disponibilidade de horários, a fim de utilizar } \\
\text { softwares, jogos matemáticos tem muita coisa. Se o } \\
\text { trabalho no primeiro ano fosse mais acolhedor, mais } \\
\text { voltado para o aluno assim de fazer o cara entender } \\
\text { a matéria, oferecer mais atendimento, mais reforço, } \\
\text { trazer recursos didáticos para que eles possam } \\
\text { aprender, trocarem ideia entre eles, se unissem mais } \\
\text { eu acho que isso favoreceria. Turmas menores, por } \\
\text { exemplo, não posso ter uma turma com } 35 \text { alunos e } \\
\text { duas inclusões em uma mesma sala. }\end{array}$ \\
\hline
\end{tabular}

Fonte: Informações da pesquisa organizadas pelas autoras, 2016. 
Com o aplicar da técnica formamos uma "primeira pessoa coletiva do singular" (LEFEVRE e LEFEVRE, 2012, p.25), dando voz a uma representação social. Ao elaborarmos os discursos, as falas dos professores com quem conversamos são preservadas, podemos somente acrescentar algumas conjunções para fazermos as conexões entre as expressões-chave. Nos discursos coletivos organizados por nós, essas conjunções aparecem sublinhadas, com a finalidade de mostrar o que foi necessário acrescentar com o intento de dar fluidez ao discurso.

Nosso primeiro movimento foi o de tentar escrever um discurso para cada uma das três questões balizadoras do conversar. Após identificarmos as ECH, IC e AC na questão 2), montamos o discurso referente a essa questão. Ao elaboramos os discursos referentes às questões 3) e 4), percebemos que as ideias centrais se repetiam, acreditamos que isso aconteceu devido ao fato de que a questão 4) pode ser classificada como um complemento à questão 3) e também pela imersão em um conversar que dá voltas em torno do aprender matemática e das tecnologias usadas para esse aprender. Então, resolvemos reunir em um único discurso as respostas dadas a essas questões.

Mesmo escolhendo essa estratégia verificamos que, nesse discurso balizado pelas questões 3) e 4), ainda tinham várias referências ao uso de tecnologias pelos alunos para o aprender. Por isso, reescreveremos os discursos por tema, dando voz aos assuntos sobre os quais esses professores falaram no conversar. Sendo assim, montamos o DSC1 intitulado Tecnologias utilizadas pelos alunos, mostrado na Tabela 3, e o DSC2 que recebeu o título de Organização escolar, apresentado na Tabela 4. Na próxima seção apresentaremos e problematizaremos o DSC1 e na subsequente faremos o mesmo para o DSC2.

\section{TECNOLOGIAS ESCOLHIDAS PELOS ALUNOS PARA APRENDER MATEMÁTICA}

Ao concluirmos todas as etapas relatadas anteriormente, onde encontramos uma convergência de temas nas falas dos professores, confeccionamos o seguinte discurso com base na temática Tecnologias, apresentado na Tabela 3.

Tabela 3- Discurso do Sujeito Coletivo 1

\section{DSC 1: Tecnologias utilizadas pelos alunos}

Muitos alunos se utilizam do Youtube para ver vídeos de professores, principalmente na época onde está próximo a provas, devido a estar em casa não precisar sair. Tem gente que não vai entender a tua explicação, então eu acho legal que eles procurem outros meios de aprendizagem. Mas, tem que ter um pé atrás porque não é em tudo que a gente pode confiar. Chamei a atenção na minha turma de ontem, que a gente encontrou um vídeo que tinha a definição completamente errada e a explicação toda era galgada em coisas incoerentes e quem visse aquele vídeo ia estar aprendendo com as definições todas erradas. Eles mesmos procuram as ajudas nas salas de vídeo do Youtube e não procuram no atendimento. Tem muito site que tem coisas erradas. Aí eles vão construir um conceito todo em cima de algo que está errado, isso ocorre bastante. Entretanto, eles pediram para gravar as minhas aulas e eles mesmos colocaram no Youtube para estudar. Então eu acho que é um bom recurso, porque acho que a gente não vai atingir $100 \%$ dos alunos, por melhor professor que tu seja. Prestar atenção em aula é muito melhor porque eles não precisam usar o tempo fora para tentar aprender aquilo que eu estou explicando e eu estou ali para explicar, para tirar as dúvidas e no vídeo não vai ter. Eles poderiam procurar um livro, eles desconhecem o que é um livro. Não costumam fazer isso. Eles utilizam um ou outro software, uns trazem no celular aplicativos que fazem gráficos, o GeoGebra, principalmente. Eu tenho toda a parte de funções montada no GeoGebra mas, em sala de aula tu não consegue trabalhar com isso porque quando tu leva uma turma com 40 alunos para um laboratório, eles vão 
mexer na internet, vão fazer outras coisas, menos fazer o que a gente tá propondo, então por isso eu acabo não levando. Não adianta só ter o programa, se tu não sabe calcular ele vai te dar uma resposta e tu vai aceitar. O programa faz para ti muitas coisas, ninguém tá indo contra as tecnologias, mas eu não posso deixar acreditar em tudo que eu recebo como resposta. Eles têm muita dificuldade em notação por não estarem acostumados, muitas vezes botavam parênteses para que ele entenda uma expressão inteira, então esse tipo de coisa dá muito erro quando eles vão programar, botei no quadro a expressão que ele tinha escrito no computador e a resposta que o celular tinha dado para ele e aí a gente chegou à conclusão que do jeito que ele escreveu, o computador tinha entendido de outra maneira. No ano passado até fiz um grupo dos meus alunos no facebook e comecei postar vídeo aulas que eu assistia, para que eles assistissem, mas não surtiu efeito. Eu colocava as listas de exercício, me comprometi a olhar o facebook todos os dias para responder as perguntas deles. Eles podiam fazer perguntas da lista, onde eles mesmos poderiam trocar, eu teria a oportunidade de corrigir alguma coisa e eu também ficaria responsável por responder questões todos os dias, só que acabou não colando. Para isso eles não gostaram do facebook, para tirar dúvidas eles não entravam no facebook, o facebook ficou chato. Algo que seria bastante útil para nós seria lousa interativa, que seria um recurso extremamente interessante, mas eu não sei se mudaria muita coisa mesmo. Outra situação seria se tivesse laboratório de informática com mais disponibilidade de horários, a fim de utilizar softwares, jogos matemáticos tem muita coisa. Eles (os alunos) podem vir no meu atendimento, na minha sala e pegar os livros que eles quiserem, eu empresto, eles podem levar para casa, fazerem exercícios de outros livros, eles têm acesso as minhas provas gabaritadas, eles podem levar, tirar xerox, vir no meu atendimento, perguntar... a gente tem o recurso do atendimento e eles não aproveitam. Parece que tudo que o professor disponibiliza, não presta. Aí eles pegam o primeiro vídeo que vai lá na busca do assunto que eles querem e aquilo tá certo. Entretanto, eu acho que se nós mesmos fizéssemos os nossos vídeos, eles iam optar por assistir o vídeo e não prestar atenção em aula. Fazer os alunos pesquisarem, ensinar o colega, despertar sobre aquele assunto e porque que aquilo ali que ele está conjecturando é válido. $O$ aluno vai ter que se comprometer muito mais, ele vai ter que trabalhar, não vai ter só que receber as informações, ele que vai ter que buscar as informações, ver se os argumentos se encaixam, se são coerentes, então isso complica bastante. $O$ aluno que tem que raciocinar sobre aquilo que ele tá lendo, e só isso já é uma dificuldade, e o professor também vai ter que ter muito mais trabalho porque fora da aula ele vai ter que se comprometer muito mais, porque ele vai preparar como o aluno vai ler uma sequência de instruções e vai chegar na conclusão que o conteúdo precisa e a aplicação daquele conteúdo, então é muito mais difícil. Quando eles perceberem vai melhorar, tanto a educação como um todo quanto para eles mesmo. Que eles se comprometam e percebam que o futuro deles passa por aqui, pela educação, pelas relações e por outras coisas mais.

Fonte: Discurso organizado pelas autoras, 2016.

Inicialmente, no DSC1, percebemos que vídeos postados no YouTube são recursos procurados pelos estudantes para o aprender, mas que essa procura nem sempre é feita de modo responsável, como dito pelos professores: "Aí eles pegam o primeiro vídeo que vai lá na busca do assunto que eles querem e aquilo tá certo". BAUMAN (2001) refere-se a uma postura imediatista da sociedade, que pode demostrar uma falta de preocupação com as consequências das escolhas.

Mais adiante, no discurso, os professores também chamam atenção para o fato de os alunos não utilizarem livros impressos como material de consulta. Isso está expresso no trecho "Eles poderiam procurar um livro, eles desconhecem o que é um livro" (DSC1). Embora o livro não seja uma tecnologia digital e também não garanta que tudo esteja correto, do ponto de vista científico, ele ainda é a tecnologia referenciada pelos professores. Foi o seu aparecimento que fez com que os conhecimentos deixassem de ficar na oralidade e posteriormente propiciou a organização das informações em enciclopédias, passo anterior à organização das informações no "ciberespaço, a região dos mundos virtuais, por meio do qual as comunidades descobrem e constroem seus objetos 
e conhecem a si mesmas como coletivos inteligentes" (LÉVY, 2010, p.166, grifo do autor). Considerando que muitos educandos elegeram a tecnologia digital como mediadora nas suas interações diárias em vez dos livros impressos, conforme DSC1, nós docentes podemos proporcionar discussões acerca da veracidade das informações encontradas nos diferentes referenciais, do quanto a informação pode ser manipulada, e que é preciso conhecer sobre a reputação das fontes escolhidas para a utilização nos seus estudos e confecção de atividades. Nessa perspectiva de diálogo pode acontecer a construção coletiva, entre professores e estudantes, de um material de consulta propiciando uma ação em direção à autonomia do estudante em relação ao seu próprio aprender.

Embora existam algumas tentativas, por parte dos docentes, de criar espaços para a convivência, identificamos a negação dos alunos em relação às propostas de seus professores, talvez porque são seja uma prática recorrente e culturalmente instaurada, ou seja, considerada pela comunidade escolar como usual:

Eles (os alunos) podem vir no meu atendimento, na minha sala e pegar os livros que eles quiserem, eu empresto, eles podem levar para casa, fazerem exercícios de outros livros, eles têm acesso as minhas provas gabaritadas, eles podem levar, tirar xerox, vir no meu atendimento, perguntar...a gente tem o recurso do atendimento e eles não aproveitam. Parece que tudo que o professor disponibiliza, não presta. Aí eles pegam o primeiro vídeo que vai lá na busca do assunto que eles querem e aquilo tá certo. Entretanto, eu acho que se nós mesmos fizéssemos os nossos vídeos, eles iam optar por assistir o vídeo e não prestar atenção em aula. (DSC1)

Devido a relação patriarcal que é encontrada nas escolas, centrada na autoridade, no controle e na subordinação (MATURANA, 2004), os alunos ainda não estão acostumados com um relacionamento em que eles tem acesso ao professor para trocar ideias sobre os conteúdos, com uma postura mediadora do professor em relação ao seu aprender. Esse professor quer ajudar esses estudantes a encontrarem os meios para seus aprenderes, está buscando uma interação, o estabelecimento de um diálogo com os seus alunos, mas suas realidades, formas de compreenderam e agirem são diferentes, dificultando a efetivação dessa interação.

O professor sente-se negado pelos seus alunos em suas tentativas de aproximação, mesmo quando ele tenta propor algo diferente através do uso das tecnologias que já são usadas pelos estudantes. No conversar, sempre que falamos no uso de tecnologias pelos alunos apareceu alguma forma de negação, ou alguma forma de aproximação frustrada. São elas:

Eles mesmos procuram as ajudas nas salas de vídeo do Youtube e não procuram no atendimento [...] Eu tenho toda a parte de funções montada no GeoGebra mas, em sala de aula tu não consegue trabalhar com isso porque quando tu leva uma turma com 40 alunos para um laboratório, eles vão mexer na internet, vão fazer outras coisas, menos fazer o que a gente tá propondo, então por isso eu acabo não levando[...] Para isso eles não gostaram do facebook, para tirar dúvidas eles não entravam no facebook, o facebook ficou chato. (DSC1)

Como melhorar este relacionamento e evitar as frustações? Talvez proporcionando espaços de conversação e recorrendo na aproximação com os alunos pela tecnologia, tentando estabelecer uma cultura de aceitação, na qual alunos e professores são considerados indivíduos legítimos em uma relação, podendo ambos proporem atividades diferenciadas (MATURANA e VERDEN-ZOLLER, 2004). Para que uma nova cultura emerja precisamos repetir posturas que são diferenciadas do que está posto como o usual, até que elas não sejam mais consideradas como 'diferentes', até o momento em que essas outras formas de trabalho não sejam mais estranhadas pelos nossos pares e alunos e sim compreendidas e validadas. 
Os trechos do DSC1 destacados anteriormente e o citado a seguir mostram algumas tentativas de criação desses espaços de convivência.

eles pediram para gravar as minhas aulas e eles mesmos colocaram no Youtube para estudar. Então eu acho que é um bom recurso, porque acho que a gente não vai atingir $100 \%$ dos alunos, por melhor professor que tu seja [...] No ano passado até fiz um grupo dos meus alunos no facebook e comecei postar vídeo aulas que eu assistia, para que eles assistissem, mas não surtiu efeito [...] Eles podiam fazer perguntas da lista, onde eles mesmos poderiam trocar, eu teria a oportunidade de corrigir alguma coisa e eu também ficaria responsável por responder questões todos os dias, só que acabou não colando. (DSC1)

Quando a proposta de interação mediada pela tecnologia partiu dos alunos, foi considerada um bom recurso pelos professores. Porém, quando a proposta de interação pelo facebook foi implementada pelo professor essa não foi validada pelos seus alunos. Isso nos leva a questionar por quê? O que aconteceu? Será que lazer não combinar com aprender? Será que aprender tem hora e lugar? Será que interação nas redes sociais não tem relação com escola, professor e Matemática? Não sabemos o que aconteceu, talvez o professor também não saiba. Cabe a ele se perguntar, perguntar aos estudantes. Quem sabe desfiá-los a criar esse espaço, dar a eles o protagonismo. Não sabemos se isso dará certo, estamos no exercício de pensar e conjecturar, tentando respeitar a autonomia dos educandos para o aprender (FREIRE, 2013), e quem sabe, assim, dar vasão para que propostas conjuntas possam começar a aparecer.

Outro ponto levantado pelos professores traz à tona importância da sintaxe matemática no emprego dos recursos tecnológicos. A utilização correta de expressões e símbolos matemáticos propicia a interação com vários softwares e isso pode provocar o uso recorrente da linguagem matemática e a compreensão de seu significado.

Não adianta só ter o programa, se tu não sabe calcular ele vai te dar uma resposta e tu vai aceitar. O programa faz para ti muitas coisas, ninguém tá indo contra as tecnologias, mas eu não posso deixar acreditar em tudo que eu recebo como resposta. Eles têm muita dificuldade em notação por não estarem acostumados, muitas vezes botavam parênteses para que ele entenda uma expressão inteira, então esse tipo de coisa dá muito erro quando eles vão programar, botei no quadro a expressão que ele tinha escrito no computador e a resposta que o celular tinha dado para ele e aí a gente chegou à conclusão que do jeito que ele escreveu, o computador tinha entendido de outra maneira. (DSC1)

A situação contada pelo professor descreve uma oportunidade de interação com o seu aluno, na qual eles percebem que o uso da tecnologia sem o rigor matemático, não trará resultados corretos nas operações resolvidas. O educando percebeu que algo não estava indo bem, comunicou ao seu professor e eles juntos chegaram às conclusões cabíveis naquele contexto.

Como nos diz Freire (2013):

O educador democrático não pode negar-se o dever de, na sua prática docente, reforçar a capacidade crítica do educando, sua curiosidade, sua insubmissão. Uma de suas tarefas primordiais é trabalhar com os educandos a rigorosidade metódica com que devem se aproximar dos objetos cognoscíveis. (FREIRE,2013, p.28)

Trazendo essa reflexão de Freire para o operar da tecnologia digital com os objetos cognoscíveis encontramos uma certa dúvida do professor de como utilizar as tecnologias digitais para o ensinar e de se ele necessita desses recursos para realizar seu trabalho. Também percebemos uma certa incredulidade sobre o uso dessas tecnologias para o aprender de seus alunos. 
laboratório de informática com mais disponibilidade de horários, a fim de utilizar softwares, jogos matemáticos tem muita coisa. (DSC1)

Podemos ter à disposição os recursos tecnológicos, mas precisamos utilizá-los para além da difusão do conhecimento do professor, como nos diz Lévy (2010) centrar as suas atividades no acompanhamento e na gestão das aprendizagens. Talvez seja por isso que o professor diz: "...mas eu não sei se mudaria muita coisa mesmo" (DSC1).

A seguir mostraremos o próximo discurso, que foi organizado por nós, centrado nas discursividades dos professores. Essas percepções estão relacionadas às questões que os intrigam sobre o contexto da organização escolar e também aos aspectos relacionados com organização da Matemática no currículo escolar.

\section{A ORGANIZAÇÃO ESCOLAR E O APRENDER MATEMÁTICA}

No decorrer da pesquisa, percebemos as inquietações dos professores sobre a organização escolar no sentido de essa afetar a sua ação pedagógica. Tais inquietações incluem o currículo de Matemática, tanto do Ensino Fundamental quanto do Ensino Médio, as distribuições de cotas, as formas ou a falta de acolhimento ao estudante e a configuração da Educação Inclusiva, como mostra discurso coletivo que apresentamos na Tabela 4.

Tabela 4- Discurso do Sujeito Coletivo 2

\section{DSC 2: Organização Escolar}

Eles estão vindo com uma baita defasagem do Ensino Fundamental, mas isso não é de agora, isso faz tempo. Antes eles corriam atrás, eu já tive alunos que vieram sem saber nada do fundamental e eu disponibilizava livros de fundamental e eles corriam atrás e eles conseguiam. Cada vez essa deficiência tá maior. Eu acho que o ideal seria uma mudança de currículo, reformulação da divisão de conteúdos e ementa das disciplinas, então eu acredito que fazendo essa mudança de currículo, a gente consegue prever, um bimestre, quatro meses, pra fazer uma revisão, porque acredito que seja muito mais fácil a gente conseguir fazer com que ele tenha aquela cultura de estudar, aquele comprometimento, com uma matéria que ele já viu, do que com uma matéria que ele nunca viu. A gente conseguiria fazer um trabalho melhor no Ensino Médio, se o Ensino Fundamental fosse embasado de outra maneira. Se não tivesse tanto conteúdo, se fosse estruturado de uma maneira diferente, se os próprios professores no Ensino Fundamental fossem apaixonados pelo que fazem...Acho que ajudaria bastante, que fosse trabalhado o conceito de aprendizagem Matemática no Ensino Fundamental, nas séries iniciais principalmente com os pedagogos, que trabalham nas séries iniciais, acho que um dos grandes problemas desse déficit, desse ódio da Matemática é oriundo da concepção desses professores das séries iniciais da parte pedagógica, o trabalho deveria ter sido feito desde o Ensino Fundamental. E aí trabalhar a Matemática realmente como ela é, não como uma decoreba. Então eu acho que o Ensino Fundamental tem que ser melhorado. Tem alunos que sabem bastante Matemática, que tem facilidade. Eles poderiam ajudar aos outros, procurarem na internet sites confiáveis, pedindo a nossa ajuda. Irem na biblioteca pegar livros, perguntando a nossa indicação, a gente indicaria bons livros para eles terem um norte no estudo. Se o trabalho no primeiro ano fosse mais acolhedor, mais voltado para o aluno assim de fazer o cara entender a matéria, oferecer mais atendimento, mais reforço, trazer recursos didáticos para que eles possam aprender, trocarem ideia entre eles, se unissem mais eu acho que isso favoreceria. Turmas menores, por exemplo, não posso ter uma turma com 35 alunos e duas inclusões em uma mesma sala. Tem coisas que eu vejo no nosso currículo que são ultrapassadas, que ninguém utiliza mais e a gente continua trabalhando. Fazer currículo direcionado para o curso, por exemplo, eu acho que a Matemática do nosso curso de informática tem que ser uma Matemática com a matéria do Ensino Médio, mas que ela também pegasse aquela parte de lógica, a parte de Matemática discreta, eu não consigo acreditar num Ensino Médio 
integrado, eu dando a mesma aula para o curso de automação e para o curso de informática. Toda a estrutura da escola mudou e a gente tem que acompanhar isso. Escolas públicas no Ensino Fundamental, tem que fazer recuperações até o aluno atingir a aprovação, então isso desestimula o professor de fazer um trabalho, porque ele vai ter que fazer uma avaliação, se o aluno não conseguir atingir as metas, ele vai ter que fazer outro, e outro, e outro... Tudo para que o professor se desestimule e não consiga trabalhar todos os conteúdos que o Ensino Fundamental aborda, então eu acho que a gente poderia tentar pensar em alguma coisa, a gente tem que quebrar um paradigma. Eu acredito que esse grande problema que nós estamos enfrentando aí na educação, vem do fato de hoje nós abrirmos as portas das escolas para todos, todos alunos, independente da classe social, tem as condições de estudar no IF, então consequentemente tem que prever que o nível desse aluno que vai chegar aqui é menor. Nós temos as cotas, esse ano vai ter cotas para deficientes, então com certeza vão ter mais deficientes no ano que vem estudando aqui e a gente tem que se adequar a esse novo modelo de escola e eu, como professor me pergunto muito, até quando eu estou acompanhando esse movimento? O meu aluno hoje em dia não é o mesmo, o meu aluno há dez anos, então acho que a gente como professor deve mudar também, porque tudo tá mudando.

Fonte: Discurso organizado pelas autoras, 2016.

Para começarmos a análise do DSC2, destacamos a ideia de cooperar que se fez presente no trecho a seguir:

Tem alunos que sabem bastante Matemática, que tem facilidade. Eles poderiam ajudar aos outros, procurarem na internet sites confiáveis, pedindo a nossa ajuda. Irem na biblioteca pegar livros, perguntando a nossa indicação, a gente indicaria bons livros para eles terem um norte no estudo (DSC2)

Maturana (2009) afirma que nós seres humanos somos seres cooperativos e vivemos em sociedade. Para que a cooperação seja experienciada entre os estudantes existe a necessidade de aceitação uns dos outros como legítimos na convivência. Propiciar espaços cooperativos para potencializar o aprender, faz parte das atribuições de gestão do educador. Se nesses espaços criarmos a oportunidade de ouvir; e saber ouvir para tentar entender qual é a dificuldade do outro, poderemos potencializar e viabilizar processos, atitudes, atividades e ações cooperativas.

Percebemos que a preocupação com o acolhimento e a aceitação dos novos estudantes nesse novo espaço e a cooperação aparecem juntas no trecho seguinte:

Se o trabalho no primeiro ano fosse mais acolhedor, mais voltado para o aluno assim de fazer o cara entender a matéria, oferecer mais atendimento, mais reforço, trazer recursos didáticos para que eles possam aprender, trocarem ideia entre eles, se unissem mais eu acho que isso favoreceria. (DSC2)

Entendemos que espaços de convivência, nos quais as opiniões dos estudantes são escutadas, suas experiências em relação aos seus aprenderes são partilhadas, existirão se a emoção que conduzir esses locais for o amor. Segundo Maturana (2004, p. 45) "A emoção que estrutura a coexistência social é o amor, ou seja, o domínio das ações que constituem o outro como legítimo outro em coexistência". Sem o amor não há a aceitação do outro como legítimo, e isso é o fundamento do cooperar na troca de vivências. Aceitar o outro como legítimo, não implica em concordar com tudo que o outro diz, mas aceitar e respeitar o fato de que ele pode ter uma opinião diferente da nossa. Não contar com essa diversidade de opiniões é, de certo modo, negar o outro, deixar de considerar a opinião do outro como legítima.

No DSC 2 encontramos o cuidado com o acolhimento ao aluno, mas no mesmo discurso também nos deparamos com a busca da culpa pelas atitudes desinteressadas dos alunos em relação a Matemática, 
o que desencadeia a negação do professor em relação aos seus colegas que trabalham no Ensino Fundamental. 0 trecho a seguir mostra essa reação:

Acho que ajudaria bastante, que fosse trabalhado o conceito de aprendizagem Matemática no Ensino Fundamental, nas séries iniciais principalmente com os pedagogos, que trabalham nas séries iniciais, acho que um dos grandes problemas desse déficit, desse ódio da Matemática é oriundo da concepção desses professores das séries iniciais da parte pedagógica, o trabalho deveria ter sido feito desde o Ensino Fundamental. E aí trabalhar a Matemática realmente como ela é, não como uma decoreba. Então eu acho que o Ensino Fundamental tem que ser melhorado. (DSC2)

Embora, os estudantes cheguem no Ensino Médio atravessados por algumas experiências de negação em relação a Matemática, lembramos que essas interações, dos professores com seus alunos, "apenas desencadearão mudanças e não especificarão o que acontecerá com eles" (MATURANA, 2014a, p. 69). Ainda para esse mesmo autor (2014b), o agente externo não determina o que acontece no sistema e isso acontece porque somos sistemas determinados estruturalmente, por isso, qualquer interação poderá desencadear mudanças que são determinadas por nós mesmos. Compreendendo dessa maneira as interações e as implicações dessas em cada ser, podemos continuar perturbando os nossos alunos na tentativa de atravessá-los com novas considerações e possibilidades para o aprender e, quem sabe, provocar mudanças de comportamento desses estudantes em relação à Matemática e seus conceitos e em nós professores nas formas de acompanhar o seus aprenderes.

O professor aponta que a maneira com que o acompanhamento da aprendizagem é validado, com sucessivas provas para substituição de notas, feitas no Ensino Fundamental, é fator desencadeador da falta de interesse, tanto dos docentes, quanto dos discentes.

Escolas públicas no Ensino Fundamental, tem que fazer recuperações até o aluno atingir a aprovação, então isso desestimula o professor de fazer um trabalho, porque ele vai ter que fazer uma avaliação, se o aluno não conseguir atingir as metas, ele vai ter que fazer outro, e outro, e outro... Tudo para que o professor se desestimule e não consiga trabalhar todos os conteúdos que o Ensino Fundamental aborda, então eu acho que a gente poderia tentar pensar em alguma coisa, a gente tem que quebrar um paradigma. (DSC2)

As recuperações estão previstas na Lei de Diretrizes e Bases da Educação Nacional (LDB 9394/96) Art24, inciso V, com o seguinte texto: "e) obrigatoriedade de estudos de recuperação, de preferência paralelos ao período letivo, para os casos de baixo rendimento escolar, a serem disciplinados pelas instituições de ensino em seus regimentos". Esse texto tem várias interpretações em diversas instituições de ensino. Muitas vezes não estão contemplados no regimento da escola as recuperações paralelas e, em alguns casos, essas são sinônimos de novas avaliações, ou seja, são realizadas novas provas sem que diálogos, orientações, e estudos direcionados para a compreensão de conceitos a partir da dificuldade e dúvida do estudante sejam realmente feitos.

Ao entender que esses alunos chegam na instituição com muitos déficits nos seus aprenderes, os professores fazem uma reflexão sobre o que poderia ajudar esses estudantes.

Eu acho que o ideal seria uma mudança de currículo, reformulação da divisão de conteúdos e ementa das disciplinas, então eu acredito que fazendo essa mudança de currículo, a gente consegue prever, um bimestre, quatro meses, pra fazer uma revisão, porque acredito que seja muito mais fácil a gente conseguir fazer com que ele tenha aquela cultura de estudar, aquele comprometimento, com uma matéria que ele já viu, do que com uma matéria que ele nunca viu. A gente conseguiria fazer um trabalho melhor no Ensino Médio, se o Ensino Fundamental fosse embasado de outra maneira. Se não tivesse tanto conteúdo, se fosse estruturado de uma maneira diferente, [...]. Tem coisas que eu vejo no nosso currículo que são ultrapassadas, que ninguém utiliza mais e a gente continua trabalhando. Fazer currículo direcionado para o curso, por exemplo, eu acho que a Matemática do nosso curso de informática tem que ser uma 
Matemática com a matéria do Ensino Médio, mas que ela também pegasse aquela parte de lógica, a parte de Matemática discreta, eu não consigo acreditar num Ensino Médio integrado, eu dando a mesma aula para o curso de automação e para o curso de informática. Toda a estrutura da escola mudou e a gente tem que acompanhar isso. (DSC2)

Os professores demonstram estarem presos a um currículo que não atende mais as necessidades de seus estudantes, acham que o fazer docente precisa ser diferente, mas que eles ainda não sabem como fazer e apontam para uma mudança oficial no currículo existente. Segundo Maturana "se quisermos compreender qualquer atividade humana, devemos atentar para a emoção que define o domínio de ações na qual aquela atividade acontece" (2014b, p.138). Esses professores estão em uma situação frente ao currículo estabelecido institucionalmente como se esse fosse intocável, e que eles não têm autonomia para a sua gestão e desse modo, estão negando a si próprios, suas observações e as suas vontades para que possam cumprir esse currículo à risca.

Chamam atenção para o fato de que as políticas de ingresso através das cotas, raciais e sociais, e a inclusão de alunos com necessidades especiais também estão impulsionando para que uma mudança seja efetivada.

Eu acredito que esse grande problema que nós estamos enfrentando aí na educação, vem do fato de hoje nós abrirmos as portas das escolas para todos, todos alunos, independente da classe social, tem as condições de estudar no IF, então consequentemente tem que prever que o nível desse aluno que vai chegar aqui é menor. Nós temos as cotas, esse ano vai ter cotas para deficientes, então com certeza vão ter mais deficientes no ano que vem estudando aqui e a gente tem que se adequar a esse novo modelo de escola e eu, como professor me pergunto muito, até quando eu estou acompanhando esse movimento? (DSC2)

Entendemos essa "queixa" enunciada, nesse discurso, como uma fragilidade do professor, uma insegurança em lidar com as diferenças, com o fato de que todos somos únicos. Fomos formados para lidar com a maioria, somos oriundos da escola que pensa que todos compreendem ou devem compreender o que o professor diz, a escola está estruturalmente organizada para isso; é a metáfora do tubo, o que é dito de um lado é ouvido do outro, e esse ouvido é sinônimo de compreendido.

A inclusão de alunos com necessidades especiais na rede regular de ensino com a redação atualizada na Lei 12796 de 2013, a qual no artigo 4², inciso III traz a seguinte escrita: "atendimento educacional especializado gratuito aos educandos com deficiência, transtornos globais do desenvolvimento e altas habilidades ou superdotação, transversal a todos os níveis, etapas e modalidades, preferencialmente na rede regular de ensino". Acreditamos que precisam ser garantidas aos professores as condições necessárias para que os processos inclusivos possam ser conduzidos de forma que o aluno tenha aos seu dispor os recursos indispensáveis para sua participação do cotidiano escolar. Na lei 13.146/2015, que institui a Lei Brasileira de Inclusão da Pessoa com Deficiência, temos um detalhamento dos vários direitos da pessoa com deficiência, e entre eles o direito à educação, em estabelecimentos de ensino regular, nos quais também terão assegurados, conforme o Art.28, inciso XIII, "acesso à educação superior e à educação profissional e tecnológica em igualdade de oportunidades e condições com as demais pessoas".

$\mathrm{Na}$ instituição em que esses professores atuam existe o Núcleo de Apoio aos Portadores de Necessidades Especiais (NAPNE), que oferece as condições necessárias para atender esses alunos, bem como, é disponibilizado um monitor para acompanhar os alunos nas aulas No entanto, mesmo que a instituição ofereça alguns recursos para que essa inclusão possa ser feita de modo efetivo, um fator dessa equação ainda não está sendo observado, conforme o DSC2, o professor faz um pedido: "Turmas menores, por exemplo, não posso ter uma turma com 35 alunos e duas inclusões em uma 
mesma sala". A melhoria dessa condição é regulamentada pela resolução 39/2014 do Conselho Municipal de Educação do município sedia o instituto, na qual no Art. 7, parágrafo $1^{\circ}$ diz que:

A composição quantitativa das turmas com, no máximo, dois alunos incluídos e até duas categorias de deficiência por sala de aula, deverá obedecer ao seguinte critério: serão diminuídas quatro vagas ao ingresso do primeiro aluno incluído; mais três vagas para o segundo aluno incluído. Se o segundo aluno possuir deficiência distinta ao do segundo, serão diminuídas quatro vagas;

De acordo com essa regulamentação a turma original deveria ter 43 alunos, para que após a subtração de oito alunos resultasse nos 35 alunos dos quais o professor se refere, pois, os dois alunos inclusos nesta turma têm deficiências distintas. Fato incomum na instituição, visto que a maioria das turmas não passa de 40 alunos. Mas o número de alunos é apenas uma variável nessa equação que se apresenta de forma complexa ao professor que tenta resolvê-la, mas muitas vezes se sente angustiado e impotente diante dos fatos.

A reflexão final do discurso diz que: "O meu aluno hoje em dia não é o mesmo, o meu aluno há dez anos, então acho que a gente como professor deve mudar também, porque tudo tá mudando" (DSC2). Que mudanças serão essas? Relacionadas as tecnologias, as legislações, as relações entre professores e alunos, a ascensão das classes sociais? Podemos dizer que são várias e que estão atuando como perturbações na estrutura dos professores, mas o modo como eles reagirão será único, individual para cada professor. Cada um de acordo com as suas experiências, tenta achar uma maneira de lidar com a velocidade e intensidade dessas mudanças.

Pensamos que é pela ação conjunta, pelo comprometimento e autonomia singular que poderemos encontrar a solução para essas inquietações que vem nos desestabilizando e nos fazendo refletir sobre o processo de aprender e de ensinar a partir de nossa sala de aula, de nossas experiências, assumindo, assim, nossa reponsabilidade.

Na próxima seção trazemos as nossas considerações e sugestões sobre as problematizações dos discursos apresentadas nas seções anteriores.

\section{ALGUMAS REFLEXÕES}

Nas análises apresentadas sobre os discursos observamos que o aluno ainda não é o protagonista no seu aprender. Deslocar esse protagonismo para o aluno significa alterar a forma de operar na escola. Reorganizando o espaço da sala de aula juntos, estudantes e professores podem dar início a essa nova configuração do espaço do aprender. O comprometimento de ambos é ponto de partida para que o entrelaçamento dos saberes e das experiências vividas adquiram e ampliem as possibilidades de cooperação e de significados do próprio aprender Matemática.

Notamos que existe uma vontade de que as coisas deem certo, mas ambos professor e aluno, precisam ouvir um ao outro para que eles se percebam como legítimos na convivência escolar, pois é no cooperar que juntos vão encontrar os caminhos para o aprender. Estamos convictos do cooperar, porque somos seres cooperativos que, historicamente, não desenvolveram as suas habilidades em ambientes hostis ou competitivos, mas em ambientes de aceitação mútua.

Percebemos que o professor está ciente das mudanças que o rodeiam, tanto no que está relacionado ao uso de tecnologias no aprender e no modo como seus alunos as estão utilizando, quanto nas 
mudanças de legislação que envolvem a educação e que implicam em reorganização do espaço escolar. Mas estar ciente não significa saber como agir.

Trabalhar pedagogicamente com a tecnologia requer apropriação da tecnologia não só no sentido de saber usar, mas no sentido de compreender como tal tecnologia pode potencializar os processos de ensinar e de aprender, assim como fazer um planejamento pedagógico envolvendo o interesse e as especificidades requer, além da clareza dos conceitos e conteúdos a ensinar, conhecer o estudante, suas necessidades e formas de aprender. O tempo e o envolvimento para uma ação pedagógica como essa é diferenciado pois o que pode ser efetivo para uma turma, pode ser dispensável em um outro contexto. Constatar essa alteração na ação diária do professor nos leva a pensar que mudar afeta a própria identidade profissional bem como a compreensão dessa profissão pela sociedade.

\section{REFERÊNCIAS BIBLIOGRÁFICAS}

BAUMAN, Zygmunt. Modernidade Líquida. Rio de Janeiro: Zahar, 2011.

BRASIL. Lei n 9394 de 20 dezembro de 1996. Estabelece as diretrizes e bases da educação nacional. Disponível em: https://www.planalto.gov.br/ccivil_03/Leis/L9394.htm. Acesso em 20 mai 2016.

BRASIL, Lei $n 12711$ de 29 de agosto de 2012. Dispõe sobre o ingresso nas universidades federais e nas instituições federais de ensino técnico de nível médio e dá outras providências. Disponível em http://www.planalto.gov.br/CCIVIL_03/_Ato20112014/2012/Lei/L12711.htm. Acesso em 20 mai 2016

BRASIL. Lei n 12976 de 04 de abril de 2013. Altera a Lei no 9.394, de 20 de dezembro de 1996, que estabelece as diretrizes e bases da educação nacional, para dispor sobre a formação dos profissionais da educação e dar outras providências. Disponível em https://www.planalto.gov.br/ccivil_03/_Ato2011-2014/2013/Lei/L12796.htm\#art1 Acesso em 20 mai 2016.

BRASIL. Lei n 13146 de 06 de julho de 2015. Institui a Lei Brasileira de Inclusão da Pessoa com Deficiência. Disponível em https://www.planalto.gov.br/ccivil_03/_ato20152018/2015/lei/l13146.htm Acesso em 20 mai 2016.

CONSELHO MUNICIPAL DE EDUCAÇÃO. Estabelece Diretrizes Operacionais para Educação Especial na perspectiva da Educação Inclusiva e para o Atendimento Educacional Especializado dos estudantes com Deficiências, Transtornos Globais de Desenvolvimento (TGD) e Altas Habilidades/ Superdotação para todas as etapas e modalidades da Educação Básica Pública e de Educação Infantil Privada, pertencentes ao Sistema Municipal de Educação da Cidade do Rio Grande. Resolução n. 39/2014. Rio Grande, 2014. Disponível em http://www.riogrande.rs.gov.br/smed/?page_id=3571. Acesso em 14 jun 2016.

FREIRE, Paulo. Pedagogia da autonomia: saberes necessários à prática educativa. 44. ed. Rio de Janeiro: Paz e Terra, 2013

KENSKI, Vani. Educação e Tecnologias: O novo ritmo da informação. Campinas: Papirus, 2007.

LEFEVRE, Fernando; LEFEVRE, Ana Maria. Discurso do Sujeito Coletivo: um novo enfoque em pesquisa qualitativa. (desdobramentos). 2.ed. Caxias do Sul, RS: Educs, 2005. 
LEFEVRE, Fernando; LEFEVRE, Ana Maria. Pesquisa de Representação Social: um enfoque qualiquantitativo. Brasília: Liber Livro Editora, 2.ed. 2012.

LÉVY, Pierre. Cibercultura. 3.ed. São Paulo: Editora 34, 2010.

MATURNA, Humberto; VARELA, Francisco. A árvore do conhecimento: as bases biológicas da compreensão humana. São Paulo: Palas Athena, 2001.

MATURANA, Humberto; VERDEN-ZOLLER, Gerda. Amar e brincar: fundamentos esquecidos do humano do patriarcado à democracia. São Paulo: Palas Athena, 2004.

MATURANA, Humberto. Reflexões: aprendizagem ou consequência ontogenética. Disponível em http://docplayer.com.br/1756495-Reflexoes-aprendizagem-ou-consequencia-ontogenetica.html Acesso em 05 jun 2016.

MATURANA, Humberto. Emoções e linguagem na educação e na política. Belo Horizonte: Editora UFMG, 2009.

MATURANA, Humberto. A Ontologia da realidade. 2.ed. Belo Horizonte: Editora UFMG, 2014a.

MATURANA, Humberto. Cognição, Ciência e Vida Cotidiana. 2.ed., Belo Horizonte: Editora UFMG, 2014b. 